\title{
Instrumentos de Avaliação Psicológica e a Fronteira Psicologia-Educação: Contribuições ao Debate Contemporâneo
}

A construção ou adaptação transcultural de instrumentos de avaliação é requisito imprescindível para o avanço do conhecimento científico. Neste fascículo são enfeixados artigos que apresentam resultados da elaboração de um instrumento brasileiro para avaliar estilos parentais, de uma escala que compõe um questionário sobre a conjugalidade de pais, além da adaptação e validação para adultos brasileiros de um inventário de saliência.

Outros artigos focalizam temas extremamente relevantes para a Psicologia na interface com a Educação, como as trajetórias de desempenho escolar no Ensino Fundamental, o relacionamento professor-aluno e a auto-regulação da aprendizagem, a implementação de um sistema de comunicação por troca de figuras em adolescente de população indígena, os aspectos inconscientes que permeiam as relações e práticas educativo-pedagógicas na Educação Infantil.

Os demais estudos publicados neste fascículo focalizam temáticas diversificadas e de grande interesse, como a contribuição da obra do teórico russo Yakubinsky para o estudo da linguagem, as trajetórias de vida de idosos que vivem em situação de pobreza ao longo da vida e sua influência sobre a integridade familiar, a avaliabilidade de um modelo lógico de avaliação de treinamento, o enfoque da Psicologia Positiva sobre o que promove a excelência humana, a aplicabilidade do Psicodiagnóstico de Rorschach na investigação do abuso sexual infantil e a pluralidade de definições de self que coexistem nas teorias e práticas psicológicas contemporâneas.

Abrindo o fascículo, o artigo Questionário de Percepção dos Pais: Evidências de uma Medida de Estilos Parentais, de Luiz Pasquali, da Universidade de Brasília, Valdiney Veloso Gouveia, da Universidade Federal da Paraíba, Walberto Silva dos Santos, da Universidade Federal do Ceará, Patrícia Nunes da Fonsêca, Josemberg Moura de Andrade e Tiago Jessé Souza de Lima, da Universidade Federal da Paraíba, apresenta os resultados da elaboração da versão reduzida de uma medida brasileira, que pode ser empregada para avaliar estilos parentais. Trata-se do Questionário de Percepção dos Pais - QPP. Participaram do estudo 386 estudantes do ensino fundamental, que responderam duas versões do QPP, que avaliavam a percepção dos jovens em relação ao seu pai e sua mãe. A análise de componentes principais permitiu identificar uma estrutura com dois componentes (responsividade e exigência) para ambas as versões. Os autores concluíram que existem evidências de validade fatorial e consistência interna do instrumento.

O artigo Pai e Mãe na Conjugalidade: Aspectos Conceituais e Validação de Construto, de Cilio Ziviani, Terezinha Féres-Carneiro e Andrea Seixas Magalhães, da Pontifícia Universidade Católica do Rio de Janeiro, apresenta um estudo de validação da escala Pai e Mãe na Conjugalidade (PMC), a partir da percepção dos filhos sobre o pai e a mãe, referente a diversos componentes desse construto. A PMC, ao distinguir pai e mãe na mesma variável, é parte integrante de um instrumento mais amplo, o Questionário sobre a Conjugalidade dos Pais (QCP). A amostra não-probabilística foi composta por 1.612 jovens, 678 homens e 934 mulheres, entre 18 e 29 anos. As análises apresentam evidência empírica de validação da PMC.

O artigo Adaptação e Validação do Inventário de Saliência (Salience Inventory) para Adultos Brasileiros, de Maria Célia Lassance e Jorge Castellá Sarriera, da Universidade Federal do Rio Grande do Sul, apresenta os resultados da adaptação e validação para a língua portuguesa da versão original do Salience Inventory, denominada Inventário de Saliência na adaptação brasileira. A amostra foi composta por 449 indivíduos adultos (388 mulheres e 111 homens). Os autores concluíram que o instrumento apresentou validade de construto e fornece parâmetros normativos para a população adulta com nível de escolaridade superior.

$\mathrm{Na}$ sequência, o artigo Acesso à Educação Infantil e Trajetórias de Desempenho Escolar no Ensino Fundamental, da autoria de Elaine Cristina Gardinal-Pizato, das Faculdades Integradas de Jaú, Edna Maria Marturano, da Universidade de São Paulo, Ribeirão Preto, e Anne Marie Germaine Victorine Fontaine, da Universidade do Porto, Portugal, parte do pressuposto de que a educação infantil contribui para trajetórias escolares mais favoráveis. O estudo teve por objetivo verificar o impacto do tempo de exposição à educação infantil sobre o desempenho acadêmico e avaliar o progresso escolar das crianças, na trajetória do $3^{\circ}$ ao $5^{\circ}$ ano do ensino fundamental, em função da exposição à educação infantil. Participaram 294 alunos de escolas públicas, avaliadas em seu desempenho escolar por meio do julgamento do professor e provas coletivas. Também foi aplicado o Teste de Desempenho Escolar. A análise de variância com medidas repetidas mostrou que o acesso à educação infantil foi consistentemente associado a melhor desempenho, porém um tempo maior de exposição não teve efeito adicional.

$\mathrm{O}$ artigo Relacionamento Professor-Aluno e Auto-Regulação da Aprendizagem no $3^{\circ}$ Ciclo do Ensino Médio Português, de Ângela Sá Azevedo, Paulo Cesar Azevedo Dias, Ana Salgado, Teresa Guimarães, Isabel Lima, Andreia Barbosa, Dora Fonte e Ana Rita Fernandes, da Faculdade de Filosofia da Universidade Católica Portuguesa, Braga, Portugal, explorou a relação entre a percepção do comportamento do professor e auto-regulação da aprendizagem na Matemática. Participaram do estudo 625 alunos do $3^{\circ}$ ciclo do Ensino Médio Português ( $\left(7^{\circ}\right.$ ao $9^{\circ}$ anos) e foram aplicados 
os questionários QIPBásico e IPAAr. Os resultados permitiram detectar diferenças nas variáveis investigadas em função do sexo, da idade, do ano de escolaridade e do número de retenções, do nível educacional dos pais, do sexo do professor de Matemática e do número de anos com o mesmo professor.

O artigo Integridade Familiar: Especificidades em Idosos Pobres, de Filipa Daniela Marques e Liliana Sousa, da Universidade de Aveiro, Portugal, analisou as trajetórias de vida de pessoas idosas que viveram em situação de pobreza ao longo da vida e como elas influenciaram as suas rotas no sentido da integridade ou da desconexão familiar. Foi aplicada entrevista semiestruturada, centrada na integridade familiar, a 12 participantes de ambos os sexos, com idades acima de 64 anos. Os resultados sugerem que algumas circunstâncias comuns na vida de famílias pobres, como conflito e/ou distância familiar, violência doméstica e/migração, múltiplas doenças crônicas severas, emprego temporário e baixos rendimentos, podem dificultar a conquista da integridade familiar e promover a desconexão familiar.

O artigo Modelos Lógicos e Avaliações de Treinamentos Organizacionais, de Sônia Maria Souza Damasceno, Gardênia Abbad e Pedro Paulo Murce Meneses, da Universidade de Brasília, teve como objetivo propor um modelo lógico de avaliação de treinamento sobre o desempenho de uma organização pública, bem como testar sua avaliabilidade. Os autores realizaram entrevista coletiva com funcionários para identificação de treinamento capaz de alterar o desempenho da organização e entrevista individual para seleção de indicadores de desempenho organizacional sensíveis ao treinamento. Também realizaram entrevista com vistas à seleção de material para proposição do modelo e grupo focal para validação do modelo lógico. O estudo conclui que o modelo lógico proposto permitiu elucidar as relações entre treinamento e desempenho organizacional, ainda que a avaliabilidade do curso não tenha sido plenamente constatada.

$\mathrm{O}$ artigo Programa de Comunicação Alternativa Readaptado para uma Adolescente Kaingang, da autoria de Lúcia Gouvêa Buratto e Maria Amelia de Almeida, Maria da Piedade Resende da Costa, descreve a implementação do Sistema de Comunicação por Troca de Figuras (The Picture Exchange Communication System - PECS) em uma adolescente da população indígena Kaingang, que apresentava deficiência intelectual e transtornos de linguagem. O sistema foi readaptado levando em consideração os valores socioculturais, morais e religiosos, bem como os hábitos e costumes da etnia. As autoras constataram que o uso do sistema de comunicação alternativa readaptado contribuiu para melhorar a comunicação não verbal e aumentar o vocabulário da adolescente indígena, que anteriormente se mostrava restrito e ininteligível.

Na sequência, o estudo Infância e Educação Infantil: Aspectos Inconscientes das Relações Educativas, de Aline
Sommerhalder e Fernando Donizete Alves, da Universidade Federal de São Carlos, teve como objetivo discutir a presença do inconsciente nas relações e práticas educativo-pedagógicas constituídas entre professor e criança na Educação Infantil. O estudo é fundamentado no referencial psicanalítico. Os autores problematizam a importância do outro humano, mais especificamente o professor, no processo formativo da criança, por meio da experiência educativa.

O artigo Excelência Humana: A Contribuição da Personalidade, de Seille Cristine Garcia-Santos, da Pontificia Universidade Católica do Rio Grande do Sul, Leandro da Silva Almeida, da Universidade do Minho, Braga, Portugal, e Blanca Susana Guevara Werlang, também da Pontifícia Universidade Católica do Rio Grande do Sul, teve por objetivo analisar, sob o enfoque da Psicologia Positiva, as explicações dos pesquisadores sobre o que promove a excelência humana e a mantém nos mais variados domínios de atuação. O estudo identificou fatores pessoais e contextuais, como as habilidades cognitivas e a prática deliberada no desempenho superior. Variáveis de personalidade também se mostram decisivas para o desenvolvimento e a manifestação da excelência, tais como: persistência, controle emocional e abertura à experiência.

Dando continuidade aos artigos publicados neste fascículo, o estudo Yakubinsky e o Círculo de Bakhtin: Aproximações, de Robson Santos de Oliveira, da Faculdade de Filosofia, Ciências e Letras de Caruaru, $e$ Maria da Conceição Diniz Pereira de Lyra, da Universidade Federal de Pernambuco, explora a contribuição de Yakubinsky para o estudo da linguagem e a sua influência sobre o Círculo de Bakhtin. Os autores articulam aspectos da formação acadêmica e do ambiente intelectual no qual Yakubinsky estava inserido, e relacionam suas contribuições com as formulações dos pensadores do Círculo de Bakhtin.

$\mathrm{O}$ artigo Uso do Rorschach na Investigação do Abuso Sexual Infantil, de autoria de Silvana Alba Scortegagna, da Universidade de Passo Fundo e Anna Elisa de Villemor-Amaral, da Universidade São Francisco, coloca em discussão a escolha de métodos apropriados para identificar crianças vítimas de abuso sexual. Entre os instrumentos de avaliação psicológica, o Método de Rorschach mostra especial utilidade para cumprir essa finalidade no cenário forense. O estudo teve como objetivo verificar a extensão e importância da utilização do Rorschach como instrumento de avaliação psicológica de vítimas de abuso sexual. Para tanto, procedeu-se a uma revisão sistemática da literatura. Os principais achados indicam a validade do Rorschach na identificação de casos de suspeitas de abuso sexual e na investigação das consequências do abuso.

Finalizando o conjunto de artigos enfeixados no presente fascículo, o estudo intitulado Self: Um Conceito em Desenvolvimento, de Lídia Suzana Rocha de Macedo e Amanda da Costa da Silveira, da Universidade Federal do Rio Grande 
do Sul, aborda as diversas definições de self que coexistem nas teorias e práticas psicológicas. As autoras argumentam que essa variedade é resultante de bases epistemológicas a partir das quais se adotam estratégias diferentes para abordar e demarcar os limites do objeto. O estudo teve como objetivo oferecer uma revisão dos conceitos de self e uma reflexão sobre como esse conceito se articula nas diferentes abordagens teóricas da psicologia.

Fechando o fascículo, a resenha Felicidade, Casamento e Satisfação Conjugal: Contribuições aos Dilemas Contemporâneos, de Laura Vilela e Souza, da Universidade Federal do Triângulo Mineiro, comenta o livro Casamento e satisfação conjugal: Um olhar da Psicologia Positiva, de Fabio Scorsolini-Comin e Manoel Antônio dos Santos.

Desejamos a todos os leitores uma leitura profícua e prazerosa.

Manoel Antônio dos Santos

Editor 